PREPARED FOR THE U.S. DEPARTMENT OF ENERGY, UNDER CONTRACT DE-AC02-76CH03073

PPPL-3991

PPPL-3991

UC-70

Time Resolved Deposition Measurements in NSTX

by

C.H. Skinner, H. Kugel, A.L. Roquemore, J. Hogan, W.R. Wampler, and the NSTX team

August 2004

$N_{\substack{\text { PRInCETOn PLASMA } \\ \text { PHYSIES LABORATORY }}}^{D}$

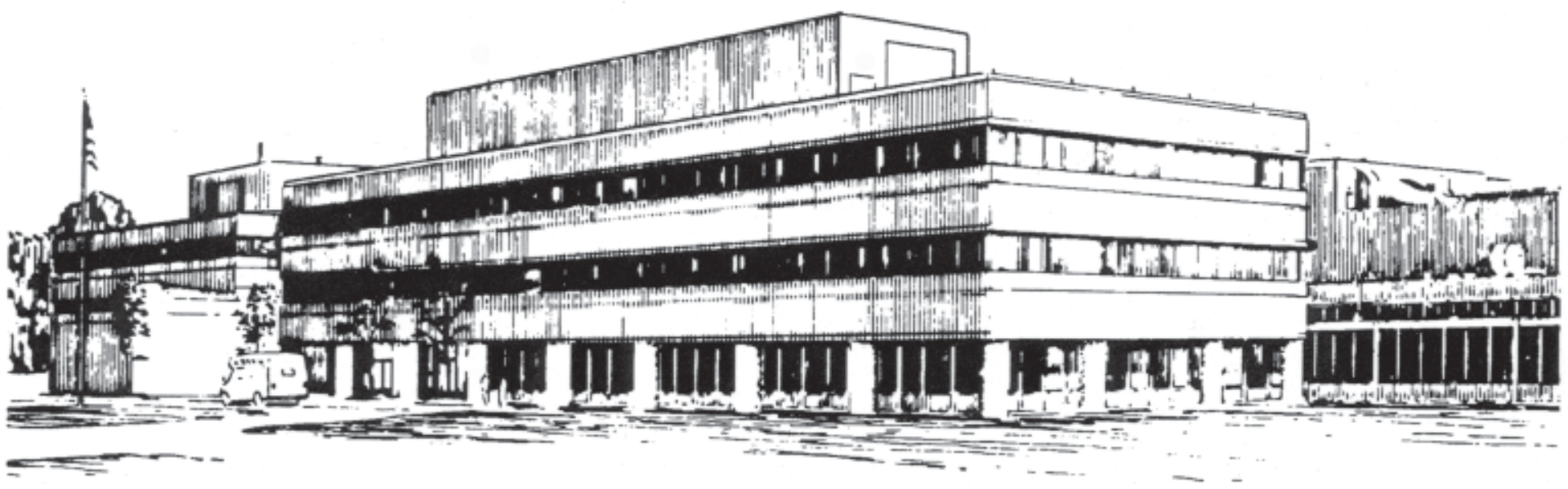

PRINCETON PLASMA PHYSICS LABORATORY PRINCETON UNIVERSITY, PRINCETON, NEW JERSEY 


\section{PPPL Reports Disclaimer}

This report was prepared as an account of work sponsored by an agency of the United States Government. Neither the United States Government nor any agency thereof, nor any of their employees, makes any warranty, express or implied, or assumes any legal liability or responsibility for the accuracy, completeness, or usefulness of any information, apparatus, product, or process disclosed, or represents that its use would not infringe privately owned rights. Reference herein to any specific commercial product, process, or service by trade name, trademark, manufacturer, or otherwise, does not necessarily constitute or imply its endorsement, recommendation, or favoring by the United States Government or any agency thereof. The views and opinions of authors expressed herein do not necessarily state or reflect those of the United States Government or any agency thereof.

\section{Availability}

This report is posted on the U.S. Department of Energy's Princeton Plasma Physics Laboratory Publications and Reports web site in Fiscal Year 2004. The home page for PPPL Reports and Publications is: http://www.pppl.gov/pub_report/

DOE and DOE Contractors can obtain copies of this report from:

U.S. Department of Energy

Office of Scientific and Technical Information

DOE Technical Information Services (DTIS)

P.O. Box 62

Oak Ridge, TN 37831

Telephone: (865) 576-8401

Fax: (865) 576-5728

Email: reports@adonis.osti.gov

This report is available to the general public from:

National Technical Information Service

U.S. Department of Commerce

5285 Port Royal Road

Springfield, VA 22161

Telephone: $1-800-553-6847$ or

(703) $605-6000$

Fax: (703) 321-8547

Internet: http://www.ntis.gov/ordering.htm 
$16^{\text {th }}$ Int. Conference on Plasma Surface Interactions in Controlled Fusion Devices, May 24-28, 2004 Portland, Me.

\title{
Time resolved deposition measurements in NSTX
}

\author{
C. H. Skinner ${ }^{* a}$, H. Kugel ${ }^{\mathrm{a}}$, A. L. Roquemore ${ }^{\mathrm{a}}$ J. Hogan ${ }^{\mathrm{b}}$, W. R. Wampler ${ }^{\mathrm{c}}$ and the NSTX team.

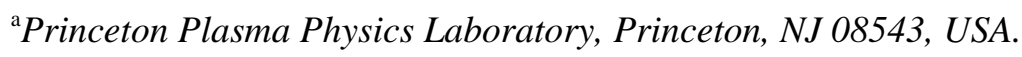 \\ ${ }^{b}$ Oak Ridge National Laboratory, Oak Ridge, TN 37831, USA \\ ${ }^{c}$ Sandia National Laboratory, Albuquerque, NM 87175, USA
}

\begin{abstract}
:
Time-resolved measurements of deposition in current tokamaks are crucial to gain a predictive understanding of deposition with a view to mitigating tritium retention and deposition on diagnostic mirrors expected in next-step devices. Two quartz crystal microbalances have been installed on NSTX at a location $0.77 \mathrm{~m}$ outside the last closed flux surface. This configuration mimics a typical diagnostic window or mirror. The deposits were analyzed ex-situ and found to be dominantly carbon, oxygen and deuterium. A rear facing quartz crystal recorded deposition of lower sticking probability molecules at $10 \%$ of the rate of the front facing one. Time resolved measurements over a 4-week period with 497 discharges, recorded $29.2 \mu \mathrm{g} / \mathrm{cm}^{2}$ of deposition, however surprisingly, $15.9 \mu \mathrm{g} / \mathrm{cm}^{2}$ of material loss occurred at 7 discharges. The net deposited mass of $13.3 \mu \mathrm{g} / \mathrm{cm}^{2}$ matched the mass of $13.5 \mu \mathrm{g} / \mathrm{cm}^{2}$ measured independently by ion beam analysis. Monte Carlo modeling suggests that transient processes are likely to dominate the deposition.
\end{abstract}

JNM keywords: P0500 Plasma-Materials Interaction, S1300 Surface Effects.

PSI keywords: Carbon deposition, quartz microbalance, Hydrocarbon radicals, NSTX, Monte Carlo simulation

PACS codes: 52.40.Hf, 52.65.Pp

Corresponding and presenting author address:

Charles H. Skinner, Princeton Plasma Physics Laboratory, POB 451, Princeton NJ 08543 USA. Email: cskinner@pppl.gov 


\section{Introduction}

Deposition of eroded material will increase dramatically with the increase of discharge duration in next-step devices and will be a major factor in the choice of plasma facing materials, tokamak operations, safety assessments and site licensing. Confidence in projecting the performance of burning plasmas is based on decades of work, mostly in machines with carbon plasma facing components[1,2]. This, together with the robustness of carbon under transient heat loads, has led to the choice of carbon as the candidate material for the ITER divertor target plate. However, measurement of the amount and location of hydrocarbon deposits in the hydrogen / deuterium phases of ITER and the development of fast and efficient tritium removal techniques[3] will be decisive in the decision of whether it will be possible to use carbon at all in the tritium phase. Deposition is a serious threat to the survival of diagnostic mirrors in long-pulse next-step devices[4]. The chemical reactions and physical process involved in the deposition of amorphous hydrogenated carbon films by hydrocarbon radicals in a tokamak are complex[5]. State-of-the-art modeling tracked chemically sputtered carbon radicals in JET discharges, however the calculations underestimated the observed retention by a factor 40[6]. The complex and varied discharge history of current tokamaks makes post-campaign 'archeological' studies of wall samples in current tokamaks of limited utility - real time measurements of the condition of interior surfaces are necessary to challenge erosion/deposition models and gain a predictive understanding of processes occurring at the plasma boundary and wall.

Quartz crystal microbalances have been widely used to monitor the growth of thin films in real time during vacuum deposition[7,8]. They have been applied to the TdeV tokamak[9], to ASDEX Upgrade[10,11], TEXTOR[12] and JET[13,14]. A capacitive diaphragm microbalance has been proposed for deposition measurements in the neutron environment of a DT burning next-step device[15]. Quartz microbalances are not sensitive to dust presumably because of the lack of mechanical coupling between the particles and quartz crystal[16]. Laboratory tests of a novel electrostatic dust detector that recorded the settling of dust on surfaces in real time were presented in ref. [16] and recent results from NSTX are reported in ref. [17]. 


\section{Time resolved deposition on NSTX.}

The National Spherical Torus Experiment (NSTX) is aimed at exploring the physics of high beta and high confinement in a low aspect ratio device[18]. Discharges span a diverse set of conditions: center column limited, diverted (both single and double null), ohmically heated, neutral beam heated, RF heated, and coaxial helicity injection[19]. Plasma facing components that are in contact with the plasma are protected by a combination of graphite and carbon fiber composite tiles. The surface temperature of the tiles at the outer divertor strike point increases to $250-500{ }^{\circ} \mathrm{C}$ during a high power discharge[20]. Two quartz microbalances[21] were mounted back-to-back on a copper plate and positioned inside a vacuum tee that was attached to a gate valve $33 \mathrm{~cm}$ below the midplane (Fig.1). The deposition geometry is generically representative of diagnostic mirrors that view the plasma through a tube. Each microbalance contained a quartz crystal that oscillated at a frequency close to $6 \mathrm{MHz}$, the precise frequency depending on the deposited mass and crystal temperature. One crystal faced the plasma and was a distance of 77 $\mathrm{cm}$ from the last closed flux surface. The second crystal faced the back of the tee, $2.5 \mathrm{~cm}$ away and is sensitive to radicals with low sticking coefficients (e.g. $\left.\mathrm{C}_{2} \mathrm{H}_{\mathrm{x}>2}[22]\right)$ that can be reflected from the walls. With the gate valve closed, the unit could be withdrawn from the machine to change out the quartz crystals when desired. The oscillation frequency was measured with a Modelock $^{\mathrm{TM}}$ system that is immune to mode hopping. The manufacturer specifies a measurement precision of $0.1 \mathrm{~Hz}$ or $0.012 \mathrm{~nm}$ for unit density per $0.25 \mathrm{~s}$ sampling time. The change in crystal frequency for a temperature change of $0.1{ }^{\circ} \mathrm{C}$ is equivalent to a deposition of $+0.006 \mu \mathrm{g} / \mathrm{cm}^{2}$. The temperature rise due to the discharge, as recorded by a thermocouple at the crystal housing, was less than $0.1^{\circ} \mathrm{C}$ and did not measurably influence the crystal frequency, though slow temperature drifts were apparent on the long term. More details are in ref. [17].

Deposition accumulated on the plasma facing crystal during a wide variety of plasma conditions generated in 497 discharges from January $13^{\text {th }} 2003$ through February $14^{\text {th }} 2003$ and is shown in Fig. 2. The typical discharge duration was $0.4 \mathrm{~s}$ and the integrated duration of all 497 discharges was $196 \mathrm{~s}$. The gate valve to the microbalance was closed during boronization on January $18^{\text {th }}$ and February $6^{\text {th }}$. There is a continuous rise, averaging $0.06 \mu \mathrm{g} / \mathrm{cm}^{2}$ or $0.37 \mathrm{~nm}$ per discharge, punctuated by a sharp decrease due to material loss over 7 discharges. The density of hydrocarbon films can range from 0.9 to $2.4 \mathrm{~g} / \mathrm{cm}^{3}$ [23] and for estimating the film thickness we 
assume a density of $1.6 \mathrm{~g} / \mathrm{cm}^{3}$. While the discharges with material loss experienced disruptions, (the day was dedicated to commissioning of the real time control system) other disruptive discharges did not show material loss. The cause for this phenomenon remains unclear.

After exposure to the plasmas, the quartz crystals were retrieved for analysis. X-ray photoelectron spectroscopy (XPS) of the front facing crystal showed $87.4 \%$ carbon (as $\mathrm{C}-(\mathrm{C}, \mathrm{H}), \mathrm{C}-\mathrm{O}$, $\mathrm{C}=\mathrm{O}$, and $\mathrm{O}-\mathrm{C}=\mathrm{O}$ ), $11.3 \%$ oxygen and trace concentrations of nitrogen (as $\mathrm{C}-\mathrm{N}$ ) and boron (as $\mathrm{B}^{3+}$ ) (these percentages exclude hydrogen isotopes and helium). The carbon areal density was measured by proton scattering at $1.735 \mathrm{MeV}$ where there is a resonance in the elastic scattering cross section that enhances the signal/background. Deuterium was analyzed by counting protons from the $\mathrm{d}\left({ }^{3} \mathrm{He}, \mathrm{p}\right){ }^{4} \mathrm{He}$ nuclear reaction with an incident ${ }^{3} \mathrm{He}$ energy of $0.7 \mathrm{MeV}$. The absolute accuracy of the measurements is about $\pm 10 \%$. The deuterium and carbon areal density was 0.2 $\mu \mathrm{g} / \mathrm{cm}^{2}$ and $11.4 \mu \mathrm{g} / \mathrm{cm}^{2}$ respectively. Assuming that the surface atomic concentration of oxygen relative to carbon as measured by XPS is representative of the whole film we calculate an areal density of oxygen of $1.9 \mu \mathrm{g} / \mathrm{cm}^{2}$. The total areal density of deuterium, carbon and oxygen is then $13.5 \mu \mathrm{g} / \mathrm{cm}^{2}$ and is in excellent agreement with the total areal density of $13.3 \mu \mathrm{g} / \mathrm{cm}^{2}$ measured by the quartz microbalance. The back facing quartz crystal had $0.014 \mu \mathrm{g} / \mathrm{cm}^{2}$ deuterium and $1.21 \mu \mathrm{g} / \mathrm{cm}^{2}$ of carbon, only $10 \%$ of the deposition on the front facing crystal. This is an indication of the relative population of moderate sticking probability radicals that can survive the multiple reflections necessary to reach the back crystal.

In the 2003 data the thickness was derived by the microbalance electronics from increments in the measured frequency and the specified density of $1.6 \mathrm{~g} / \mathrm{cm}^{3}$. For 2004, a RS232 link was implemented that acquired the crystal frequency directly so that the deposited mass and thickness could be calculated manually. At this time the electrical environment of NSTX suffered from enhanced electrical pickup that affected several diagnostics. A second pair of crystals was exposed to 304 plasma discharges of total duration 136 s from $6^{\text {th }}$ February to $9^{\text {th }}$ March 2004. Nuclear reaction analysis (NRA) showed that $1.25 \mu \mathrm{g} / \mathrm{cm}^{2}$ carbon and $0.05 \mu \mathrm{g} / \mathrm{cm}^{2}$ deuterium was deposited on the plasma facing crystal corresponding to an average rate / discharge that is five times lower than in 2003. The mass derived from the total quartz crystal frequency change of $1.4 \mu \mathrm{g} / \mathrm{cm}^{2}$ was consistent with the mass measured by NRA (including oxygen) of $1.5 \mu \mathrm{g} / \mathrm{cm}^{2}$. However the 'thickness' reported by the microbalance electronics occasionally showed 
increments uncorrelated to frequency. Evidently some frequency increments were not registered correctly due to electrical interference. However the true crystal frequency was always recovered in-between discharges and correctly reflected the deposited mass as confirmed by NRA.

Figure 3 shows an example of deposition over four discharges in the 2004 campaign as calculated manually from the frequency of the plasma facing quartz crystal. A step-up in layer thickness of $0.07 \mathrm{~nm}$ is seen on the first discharge (\#112014 $800 \mathrm{kA}$, lower single null, neutral beam heated discharge) and also on the second (\#112015; 1 MA, double null, neutral beam heated discharge) but not on the subsequent similar discharges that day. The factors that cause deposition in one case and not in another are not clear, though often the deposition occurs on the first shots of the day. Also noteworthy is the continuous slow rise in deposition between discharges. The temperature of the crystal housing is also displayed in Fig. 3. The Y axis scale of both the temperature and deposition is arranged to correspond to the same crystal frequency change so the curves can be compared directly. It can be seen that the rise in deposition cannot be accounted for by a temperature drift. Condensation of pump oil is not a factor as pump oil is not observed in the NSTX exhaust (the RGA sensitivity is better than 1e-11 torr). Water is present in the RGA spectrum in the 1e-9 torr range, but only $10 \%$ oxygen is found in the deposit so any effect of water absorption must be small. The continuous slow rise in deposition may be related to the evaporation of polymer-like films after each discharge and deposition in the interpulse period as postulated by [24].

Erosion and deposition in NSTX has been studied using sample coupons and silicon marker implants attached to the vessel interior wall[25]. Figure 4 shows deposition on stainless steel and silicon wall coupons exposed to plasma operations (2521 discharges of integrated duration $821 \mathrm{~s}$ ) and 9 boronizations between September 2000 and August 2001. Nuclear reaction analysis was performed using the ${ }^{11} \mathrm{~B}\left({ }^{1} \mathrm{H},{ }^{4} \mathrm{He}\right){ }^{8} \mathrm{Be}$ reaction with a $650 \mathrm{keV}$ proton beam to measure boron; ${ }^{2} \mathrm{H}\left({ }^{3} \mathrm{He} \text {,p }\right)^{4} \mathrm{He}$ reaction with $700 \mathrm{keV}{ }^{3} \mathrm{He}$ beam to measure deuterium and Rutherford back scattering with a $1500 \mathrm{keV}$ proton beam to measure carbon. The carbon, deuterium and boron areal density showed strong poloidal and toroidal variations. Toroidally the highest deposition is near the gas injector at the Bay $\mathrm{K}$ upper divertor (toroidal $315^{\circ}$ ) and the two gas injectors in the bay L pump duct (toroidal angle $345^{\circ}$ ). 


\section{Modeling}

From a priori considerations, it seems likely that the carbon deposited on the coupons is generated by transient events such as ELMs, disruptions or plasma start-up / shut-down, rather than by steady deposition from the well-confined plasma. In order to evaluate the growth of deposited layers on the coupons directly due to carbon produced at the divertor plates during steady (e. g., intra-ELM) 'quiescent' periods, a version of the BBQ code [26,27] has been developed for the NSTX geometry. BBQ is a 3D Monte Carlo code that describes the generation of carbon impurities by plasma surface interactions and tracks the subsequent transport in the plasma scrape-off layer and edge/pedestal region. Impurity generation from physical and chemical sputtering and radiation-enhanced sublimation (RES) is included. Preliminary calculations using the configuration of NSTX pulse 108251 at a time $0.5 \mathrm{sec}$, and assuming conventional models for cross field diffusive transport, indicate that a negligible fraction (less than $1 \%$ ) of the carbon generated at the divertor plates directly reaches the outer wall region, either through flight of neutrals or via diffusion in the scrape-off layer. This amounts to less than $0.001 \mathrm{~nm}$ per discharge. However, since the outer mid-plane area of the plasma is the site of observed macroscopic turbulence on NSTX, as well as the locus of ELM-induced radial transport, such non-steady processes are likely to dominate the deposition instead.

\section{Summary and implications for ITER.}

Time resolved measurements with a quartz microbalance showed deposition of carbon oxygen and deuterium in a location on NSTX typical of diagnostics mirrors. The results confirm that methods to remove mirror deposits in-situ and shutters to limit the exposure will be crucial for ITER optical diagnostics. Deposition on the rear facing crystal suggests this may be needed even for mirrors that do not face the plasma directly. Surprisingly, material loss was observed on 7 discharges. A slow rise in deposition in the inter-pulse period was also observed and this may be related to the condensation of polymer-like films after each discharge. Modeling indicated that the deposition was not due to quiescent processes in the discharge suggesting that transients such as ELMS and disruptions and also consideration of the evaporation and condensation of polymer-like films should be taken into account in predicting the spatial distribution of 
codeposited tritium in ITER. This information will be crucial for the design and development of codeposit removal technology that will be essential to control the tritium inventory.

\section{Acknowledgments}

The authors thank W. Blanchard, B. Davis, T. Holoman, D. LaBrie, D Mastrovito, P. Roney, R.

Raman, and J. Wertenbaker for technical assistance. This work was funded by U.S. DOE Contract Nos. DE-AC02-76CH0307. Sandia is a multiprogram laboratory operated by Sandia Corporation, a Lockheed Martin Company, for the United States Department of Energy's National Nuclear Security Administration under contract DE-AC04-94AL85000. 


\section{References:}

[1] G. Federici, C. H. Skinner, J. N. Brooks, J. P. Coad, C. Grisolia, A. A. Haasz, A. Hassanein, V. Philipps, C. S. Pitcher, J. Roth, W. R. Wampler, D. G. Whyte, Nucl. Fus., 41, (2001) 1967.

[2] G. Federici et al., J. Nucl. Mater., 313-316, (2003) 11.

[3] C. H. Skinner, J. P. Coad and G. Federici, Physica Scripta (2004) in press.

[4] V. Voitsenya et al., Rev. Sci. Instrum., 72 (2001) 475.

[5] W. Jacob, Thin Solid Films, 326 (1998) 1.

[6] J. N. Brooks et al., J. Nucl. Mater., 313-316 (2003) 424.

[7] C. S. Lu and O. Lewis, J. Appl. Phys. 43 (1972) 4385.

[8] J. Janata, Principles of Chemical Sensors (Plenum Press, New York, 1990) p.55.

[9] D. Bourgoin, G. G. Ross. S. Savoie, Y. Drolet, E. Haddad., J. Nucl. Mater., 241-243 (1997) 765.

[10] V. Rhode, H. Maier, K. Krieger, R. Neu, J. Perchermaier, J. Nucl. Mater., 290-293 (2001) 317.

[11] V. Rohde, M. Mayer et al., Physica Scripta, T 102, (2003) 25.

[12] J. von Seggern, P. Wienhold, T. Hirai, B. Philipps, H. G. Esser, J. Nucl. Mater. 313-316 (2003) 439-443.

[13] H. G. Esser, G. Neil, P. Coad, G. F. Matthews, D. Jolovic, D. Wilson, M. Freisinger and V. Philipps, Fusion Eng. Des., 66-68 (2003) 855.

[14] H. G. Esser, V Philipps, M. Freisinger, P Coad, G. F. Matthews, G Neil, Proceedings of the $10^{\text {th }}$ International Carbon Workshop for Fusion Application, Juelich, September 17$19^{\text {th }}, 2003$ to be published in Physica Scripta.

[15] C. F. Counsell and C. H. Wu, Physica Scripta T91 (2001) 70.

[16] A. Bader, C.H. Skinner, A.L. Roquemore, and S. Langish, Rev. Sci. Instrum. 75, (2004) 370. 
[17] C. H. Skinner, A. L. Roquemore, A. Bader, W. R. Wampler and the NSTX team. Proceedings of the $15^{\text {th }}$ Topical Conference on High-Temperature Plasma Diagnostics, San Diego, Ca, April 19-22, 2004, to be published in Rev Sci. Instrum. (2004).

[18] E.J. Synakowski, et al., Nucl. Fus. 43 (2003)1653.

[19] R. Raman et al., Nucl. Fus., 41, 1081 (2001).

[20] D.A. Mastrovito, R Maingi, H. W. Kugel, A. L. Roquemore, Rev. Sci. Instr. 74 (2003) 5090 .

[21] Leybold Infinicon, Two Technology Place, East Syracuse,NY; model XTM2P/11231000.

[22] A. von Keudell, C. Hopf, T. Schwarz-Selinger, W. Jacob., Nucl. Fus. 39 (1999) 1451.

[23] T. Schwarz-Selinger et al., J. Appl. Phys., 86 (1999) 3988.

[24] A. von Keudell, C. Hopf, T. Schwarz-Selinger, W. Jacob, Nucl. Fus, 39 (1999) 1451.

[25] H. W. Kugel et al., J. Nucl. Mater 290 - 293 (2001) 1185.

[26] J. Hogan et al, 16th International Confererence on Fusion Energy (Montreal, 1996), IAEA Vienna, 2 (1997) 625.

[27] R. Giannella, Y. Corre, J. Hogan et al, Plasma Phys. Control. Fusion 43 (2001) 271. 


\section{Figure Captions:}

Fig. 1 Detector geometry: (a) side view. The plasma facing quartz microbalance is $77 \mathrm{~cm}$ from the last closed flux surface (LCFS). The tube between microbalance and the vacuum vessel wall is $38.5 \mathrm{~cm}$ long and for the most part, is $9.7 \mathrm{~cm}$ diameter. The rear facing quartz microbalance is $2.5 \mathrm{~cm}$ from the rear of the vacuum tee. A silicon witness coupon also faces the plasma. (b) plan view showing a close up of the detectors in the vacuum tee. The silicon coupon is above the plasma facing quartz microbalance.

Fig. 2 Overview of accumulating deposition Jan $13^{\text {th }}-$ Feb $14^{\text {th }}, 2003$. The deposition thickness in $\mathrm{nm}$ is derived from an assumed density of $1.6 \mathrm{~g} / \mathrm{cm}^{3}$.

Fig. 3 Upper curve: deposition over four discharges (112014 - 112017) on 9 April 2004 with the discharge times marked by the last digit of the shot number. Step-ups in layer thickness can be seen in the first two discharges. The lower curve displays the temperature of the crystal housing. The temperature scale (right $\mathrm{Y}$ axis) is set so that the corresponding frequency change matches the frequency change of the deposition on the left $\mathrm{Y}$ axis.

Fig. 4 Composition and areal density of deposition on (a) poloidal and (b) toroidal array of silicon coupons, $\square$ carbon; $\diamond$ deuterium; $\Delta$ boron. Zero poloidal angle is at the midplane. There are 12 bays labeled A-L and zero toroidal degrees is between bays A and L. The poloidal coupon array was located at bay $\mathrm{C}$ (toroidal $75^{\circ}$ ). The toroidal angle of the poloidal array was $75^{\circ}$. Gas injectors are at toroidal angles of $345^{\circ}$ and $315^{\circ}$. 
(a)
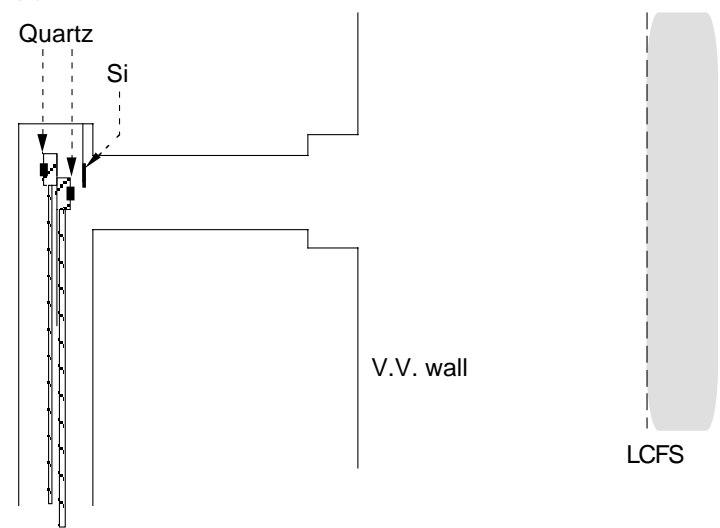

(b)

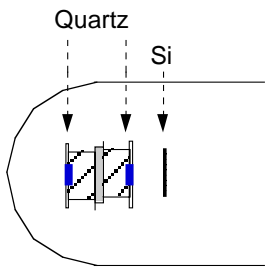

Figure 1 Detector geometry: (a) side view. The plasma facing quartz microbalance is $77 \mathrm{~cm}$ from the last closed flux surface (LCFS). The tube between microbalance and the vacuum vessel wall is $38.5 \mathrm{~cm}$ long and for the most part, is $9.7 \mathrm{~cm}$ diameter. The rear facing quartz microbalance is $2.5 \mathrm{~cm}$ from the rear of the vacuum tee. A silicon witness coupon also faces the plasma. (b) plan view showing a close up of the detectors in the vacuum tee. The silicon coupon is above the plasma facing quartz microbalance. 


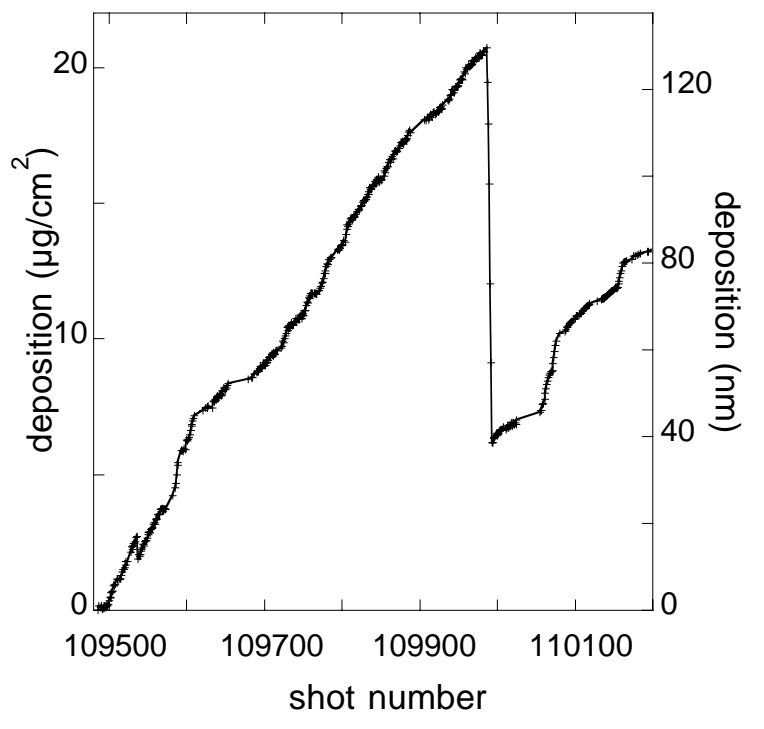

Figure 2 Overview of accumulating deposition Jan $13^{\text {th }}-$ Feb $14^{\text {th }}$, 2003. The deposition thickness in $\mathrm{nm}$ is derived from an assumed density of $1.6 \mathrm{~g} / \mathrm{cm}^{3}$. 


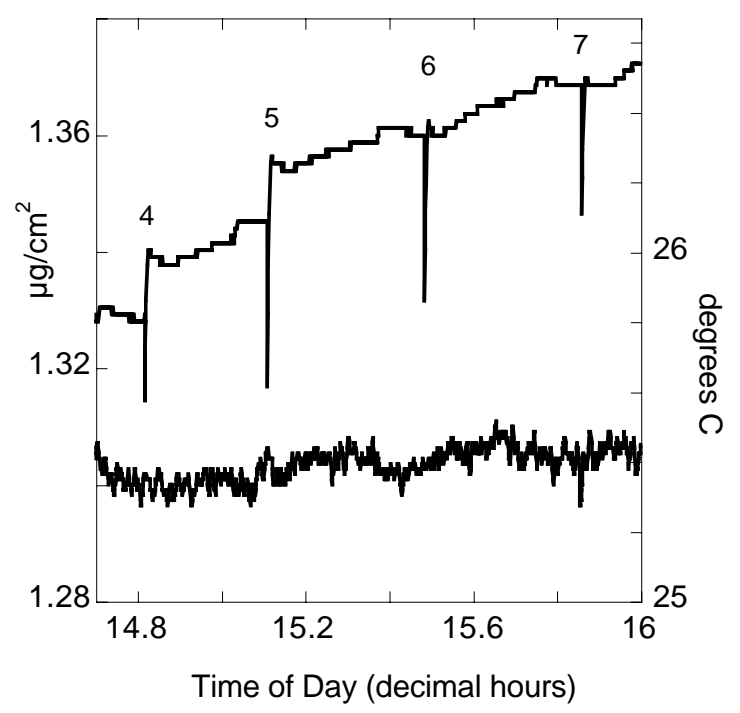

Figure 3 Upper curve: deposition over four discharges (112014 - 112017) on 9 April 2004 with the discharge times marked by the last digit of the shot number. Step-ups in layer thickness can be seen in the first two discharges. The lower curve displays the temperature of the crystal housing. The temperature scale (right $\mathrm{Y}$ axis) is set so that the corresponding frequency change matches the frequency change of the deposition on the left $\mathrm{Y}$ axis. 

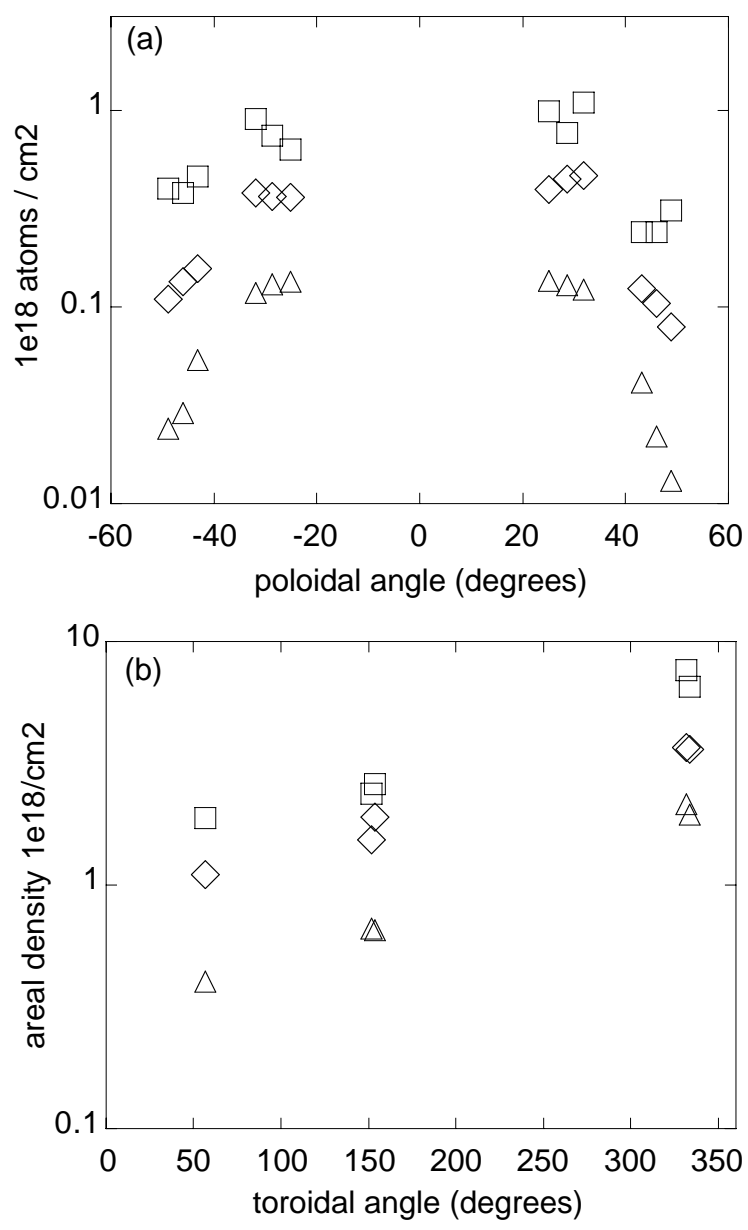

Figure 4 Composition and areal density of deposition on (a) poloidal and (b) toroidal array of silicon coupons, $\square$ carbon; $\diamond$ deuterium; $\Delta$ boron. Zero poloidal angle is at the midplane. There are 12 bays labeled A-L and zero toroidal degrees is between bays A and L. The poloidal coupon array was located at bay $\mathrm{C}$ (toroidal $75^{\circ}$ ). The toroidal angle of the poloidal array was $75^{\circ}$. Gas injectors are at toroidal angles of $345^{\circ}$ and $315^{\circ}$. 


\section{External Distribution}

Plasma Research Laboratory, Australian National University, Australia

Professor I.R. Jones, Flinders University, Australia

Professor João Canalle, Instituto de Fisica DEQ/IF - UERJ, Brazil

Mr. Gerson O. Ludwig, Instituto Nacional de Pesquisas, Brazil

Dr. P.H. Sakanaka, Instituto Fisica, Brazil

The Librarian, Culham Laboratory, England

Mrs. S.A. Hutchinson, JET Library, England

Professor M.N. Bussac, Ecole Polytechnique, France

Librarian, Max-Planck-Institut für Plasmaphysik, Germany

Jolan Moldvai, Reports Library, Hungarian Academy of Sciences, Central Research Institute for Physics, Hungary

Dr. P. Kaw, Institute for Plasma Research, India

Ms. P.J. Pathak, Librarian, Institute for Plasma Research, India

Ms. Clelia De Palo, Associazione EURATOM-ENEA, Italy

Dr. G. Grosso, Instituto di Fisica del Plasma, Italy

Librarian, Naka Fusion Research Establishment, JAERI, Japan

Library, Laboratory for Complex Energy Processes, Institute for Advanced Study, Kyoto University, Japan

Research Information Center, National Institute for Fusion Science, Japan

Dr. O. Mitarai, Kyushu Tokai University, Japan

Dr. Jiangang Li, Institute of Plasma Physics, Chinese Academy of Sciences, People's Republic of China

Professor Yuping Huo, School of Physical Science and Technology, People's Republic of China

Library, Academia Sinica, Institute of Plasma Physics, People's Republic of China

Librarian, Institute of Physics, Chinese Academy of Sciences, People's Republic of China

Dr. S. Mirnov, TRINITI, Troitsk, Russian Federation, Russia

Dr. V.S. Strelkov, Kurchatov Institute, Russian Federation, Russia

Professor Peter Lukac, Katedra Fyziky Plazmy MFF UK, Mlynska dolina F-2, Komenskeho Univerzita, SK-842 15 Bratislava, Slovakia

Dr. G.S. Lee, Korea Basic Science Institute, South Korea

Institute for Plasma Research, University of Maryland, USA

Librarian, Fusion Energy Division, Oak Ridge National Laboratory, USA

Librarian, Institute of Fusion Studies, University of Texas, USA

Librarian, Magnetic Fusion Program, Lawrence Livermore National Laboratory, USA

Library, General Atomics, USA

Plasma Physics Group, Fusion Energy Research Program, University of California at San Diego, USA

Plasma Physics Library, Columbia University, USA

Alkesh Punjabi, Center for Fusion Research and Training, Hampton University, USA

Dr. W.M. Stacey, Fusion Research Center, Georgia Institute of Technology, USA

Dr. John Willis, U.S. Department of Energy, Office of Fusion Energy Sciences, USA

Mr. Paul H. Wright, Indianapolis, Indiana, USA 
The Princeton Plasma Physics Laboratory is operated by Princeton University under contract with the U.S. Department of Energy.

\author{
Information Services \\ Princeton Plasma Physics Laboratory \\ P.O. Box 451 \\ Princeton, NJ 08543
}

Phone: 609-243-2750

Fax: 609-243-2751

e-mail: pppl_info@pppl.gov

Internet Address: http://www.pppl.gov 